\title{
The prolactin-inducible-protein (PIP): A regulatory molecule in adaptive and innate immunity
}

\author{
Vivake Umadat ${ }^{1^{*}}$, Olivia Ihedioha ${ }^{1^{*}}$, Robert Shiu $^{2}$, Jude Uzonna $^{3}$, Yvonne Myal $^{1,2 \#}$ \\ ${ }^{1}$ Department of Pathology, Faculty of Medicine, University of Manitoba, Winnipeg, Canada \\ ${ }^{2}$ Department of Physiology, Faculty of Medicine, University of Manitoba, Winnipeg, Canada; \\ \#Corresponding Author: yvonne.myal@med.umanitoba.ca \\ ${ }^{3}$ Department of Immunology, Faculty of Medicine, University of Manitoba, Winnipeg, Canada
}

Received 14 September 2013; revised 14 October 2013; accepted 21 October 2013

Copyright (C) 2013 Vivake Umadat et al. This is an open access article distributed under the Creative Commons Attribution License, which permits unrestricted use, distribution, and reproduction in any medium, provided the original work is properly cited. In accordance of the Creative Commons Attribution License all Copyrights (C) 2013 are reserved for SCIRP and the owner of the intellectual property Vivake Umadat et al. All Copyright (C) 2013 are guarded by law and by SCIRP as a guardian.

\begin{abstract}
The Prolactin-inducible-protein (PIP)/Gross Cystic Disease Fluid Protein-15 (GCDFP-15) gene is highly expressed in salivary, lacrimal and sweat glands and the protein abundantly found in the secretions that originate from these glands; saliva, tears and sweat. PIP is thus considered to be strategically located at sites viewed as the first port of entry for invading organisms. PIP is also found over-expressed under abnormal and pathological conditions of the breast and prostate. The function of PIP has yet to be defined but it has been implicated to play a role in immunity, with respect to bacterial and viral infection, cancer and fertility. Despite such predictive functions, there is still no clear demonstration of an immunoregulatory role for PIP. In this review we will focus on accumulating evidence that suggests a role for PIP in both innate and adaptive immunity. Moreover, we will discuss recent evidence that defines a modulatory role for PIP with regards to a $\mathrm{CD} 4^{+} \mathrm{T}$ cell immune response, identifying for the first time, a critical role for PIP in effective cell-mediated immunity against an intracellular pathogen.
\end{abstract}

Keywords: Prolactin-Inducible-Protein (PIP); Immunoregulation; Innate Immunity;

Adaptive Immunity

\section{INTRODUCTION}

The human Prolactin-inducible-protein (PIP)/Gross Cystic Disease Fluid Protein-15 (GCDFP-15) was first

\footnotetext{
*These authors contributed equally to this manuscript.
}

reported by Haagensen et al. [1] as an acidic protein found in abundance in gross cystic disease fluid of the breast. Independently, it was identified by Shiu and Iwasiow [2] as a glycoprotein secreted by human breast cancer cells in response to the lactogenic hormone prolactin $[3,4]$ and was designated Prolactin-inducibleprotein (PIP). PIP has also been subsequently identified to be analogous to Glycoprotein-17 (gp17) [5], Secretory Actin-Binding Protein (SABP) [6], and Extraparotid Glycoprotein (EP-GP) [7].

The PIP gene is located on chromosome 7q32-36 and is composed of 4 exons [8]. Only one 900 base mRNA transcript has been identified [3]. The protein is comprised of 146 amino acids and there is a signal peptide present on the $28^{\text {th }}$ residue [1]. PIP is synthesized as a precursor polypeptide of $12.5 \mathrm{kDa}$ and subsequent to the removal of the signal peptide; its size is reduced to 11 $\mathrm{kDa}$ [9]. The secreted protein has 3 isoforms, $11 \mathrm{kDa}, 14$ $\mathrm{kDa}$, and $16 \mathrm{kDa}$ in size, with the $14 \mathrm{kDa}$ isoform being the predominant peptide [9]. The $14 \mathrm{kDa}$ and the $16 \mathrm{kDa}$ proteins are glycosylated forms of the $11 \mathrm{kDa}$ protein.

\subsection{Expression and Secretion of PIP}

In healthy individuals, PIP expression has been associated with normal apocrine cells of the body [10]. PIP is highly expressed in the major salivary glands, lacrimal glands and sweat glands, and the protein is found abundantly in the secretions from these tissues; saliva, tears and sweat [11]. PIP is secreted from glands of the axilla, perineum and eyelid (Molls gland). As well, PIP is found in the secretions of the ear canal, bronchial submucosa and seminal vesicles [1]. PIP has also been detected in bodily fluids such as breast milk, amniotic fluid and blood $[3,12]$.

PIP is abnormally expressed under various disease 
conditions associated with apocrine cells. PIP is one of the major glycoproteins that constitutes the pathologic secretion of gross cystic disease fluid from the premenopausal disorder, gross cystic disease of the breast [10]. While its gene expression is difficult to detect in normal breast epithelium [12], PIP expression is readily detected in breast epithelium that has undergone benign apocrine metaplasia. These apocrine cells are easy to identify as they have a unique morphology as well as a granular acidophilic cytoplasm [12].

PIP is also readily detectable in breast carcinoma cells with apocrine epithelium. Cytosol from breast carcinoma samples has been shown to contain PIP in varying amounts [13], with the highest levels associated with more differentiated carcinomas, the intraductal cribriform and the comedo types [10]. PIP has been detected in as many as $93 \%$ of human breast tumor biopsies [14] and plasma levels of PIP have been shown to be useful in monitoring about 40 percent of patients with metastatic breast carcinomas [10]. Due to the coincident consistent presence of PIP in both benign apocrine metaplasia and its gene expression in most breast cancer cells, PIP is now an established marker for abnormal breast [12].

In both normal and diseased states, the expression of the PIP gene is shown to be regulated by many hormones and cytokines. For example, PIP is up-regulated by androgens, glucocorticoids, and progesterone [2] and has been shown to be influenced by the cytokines IL-4/IL-13 in breast tumors [15]. Such hormonal regulation of PIP is well documented in previous reviews $[9,16]$.

\subsection{Structure/Function of PIP}

To date, the function of PIP has not yet been elucidated, but there are many lines of evidence which suggest that its role is multifunctional. PIP is primarily thought to play a role in immune regulation, inhibition of bacterial growth, fertility, prostate and breast tumor progression, and more recently, in the formation of enamel pellicle $[17,18]$. Many of these aspects of PIP's possible function have already been well reviewed recently by Hassan et al. [16], and, except for its role in immunity, will not be covered in depth here.

The recent determination of the crystal structure of PIP [16] has provided important insights into a possible role in immunity. The crystalline structure has revealed an immunoglobulin fold composed of seven antiparallel beta-strands and seven loops [16]. The identification of the beta folds is consistent with the hypothetical model previously proposed by Caputo et al. [19] who used a homology modeling approach to elucidate a three-dimensional model of the PIP protein. At that time, these authors suggested that the possession of a common "all beta-fold" composition was characteristic of aspartic proteinases [20], and further proceeded to demonstrate that
PIP was indeed an aspartic proteinase [19].

It has also been shown that PIP has an ability to bind to numerous immunoregulatory molecules such as the CD4 molecule on T cells, immunoglobulin G (IgG), actin, and zinc $\alpha 2$-glycoprotein (ZAG), as well as non-immunomodulatory molecules, fibronectin and enamel pellicle. Importantly, the beta fold in PIP is thought to play a major role in such interactions [16,21-24]. Furthermore, PIP has been shown to bind to the glycoprotein CD4 cluster, which is found on the surface of immune cells such as T helper cells, monocytes, macrophages, and dendritic cells. These cells all have crucial roles in maintaining the adaptive and innate immune system, controlling the spread of infections and invasion of incoming pathogens [25].

\section{A ROLE FOR PIP IN INNATE IMMUNITY}

\subsection{Innate Immunity}

The innate immune system, otherwise known as the natural or first line of defense, is present at birth and relies on receptors commonly found in body fluids, tissue cells or mobile hematopoietic cells to detect microbial pathogens [26]. The innate defense is quick but lacks specificity. Among the cells that bear innate immune receptors are macrophages, dendritic cells, mast cells, neutrophils, eosinophils and natural killer (NK) cells [27]. Components of the innate immune system are responsible for the initial pathogenic contact and use anatomical barriers such as surface epithelium and mucous membrane secretions to carry out designated functions. This system protects the host from pathogen entry by providing a physical barrier and producing molecules such as mucins and other microbicidal products that help prevent the entry, attachment, and growth of harmful agents [26]. There is also a phagocytic component to the innate immune system where macrophages and neutrophils are activated upon pathogen exposure, and with the help of opsonins and complement, engulf and destroy the pathogen [26]. It is also known that physiological and inflammatory barriers greatly assist in the innate defense system. Chemokines and interleukins such as interleukin-1 (IL-1), IL-6, IL-4, IL-5, and IL-13 are key regulators of leukocytes. They signal the leukocytic action of mast cells, eosinophils, basophils, NK cells and dendritic cells during an infection and help to aid in the body's inflammatory response [26].

\subsection{PIP Involvement in First Line Defense: Inhibition of Bacterial Colonization}

Many salivary components have the ability to interact with bacterium which frequently inhabit the oral cavity and deter their expansion. This property makes saliva an 
integral part of the innate immune defense system. Molecules in saliva that contribute to this interaction include alpha-amylase, immunoglobulin A, mucins, proline-rich glycoprotein, histatins, and lysozyme [28]. PIP, which is found in saliva, can be listed among these molecules, and as such, is thought to play a role in the first line of immune defense against invading pathogens [4]. Schenkels et al. [28] demonstrated that PIP (EP-GP), which is secreted by the salivary glands [17] has the ability to bind in vitro and inhibit the growth of several bacterial strains including Gemella, Staphlococcus and Streptococcus.

Moreover, PIP is not only present in the oral cavity. PIP is found strategically located at several other ports of pathogen entry, predominately in mucosal-type tissues that produce secretions involved in the first line of innate immune defense [1]. In addition to saliva, PIP is also present in other body fluids, including tears, sweat, nasal mucus, and ear wax that are involved in the first line defense of the host [12]. Overall, PIP constitutes approximately $1 \%$ of the total proteins present in these secretions.

As well as binding oral bacteria, PIP has been shown to bind bacteria affiliated with the skin and ear canal. Using immunofluorescence strategies Schenkels et al. [28] showed PIP (EP-GP) bound to a number of bacterial strains including Streptococci, Staphylococci, and Gemella harvested from the skin and ear canal, demonstrating that the binding of PIP to these bacteria is highly specific. These studies suggest that PIP can play a major role in further inhibiting bacterial colonization of the human body.

\section{A ROLE FOR PIP IN ADAPTIVE IMMUNITY}

\subsection{Adaptive Immunity}

Adaptive immunity otherwise known as the acquired or specific immunity, relies on the expansion of lymphocytes that express highly diverse, clonally restricted antigen-specific receptors arising from rearrangements of gene segments encoded in specialized genetic loci [26]. The function of the adaptive immune response is to destroy invading pathogens and any toxins they produce. This system targets specifically foreign entities to prevent destruction of host defenses [29]. The key mediators in the adaptive response are white blood cells known as lymphocytes that produce two broad classes of responses [29]. The first is the antibody-mediated response that depends on B lymphocytes. Antibodies protect the host through a variety of mechanisms such as the neutralization of toxins, lysis of bacteria through complement activation, opsonization of bacteria to facilitate phagocytosis, and interference with adherence of bacteria/viruses to cell surfaces [25]. The other class of response is the cell-mediated response that depends on $\mathrm{T}$ lymphocytes [29]. T cell activation for subsequent effector functions is regulated by their interaction with dendritic cells, which are specialized antigen-presenting cells that are critically important for $\mathrm{T}$ cell recognition of antigens. Dendritic cells express toll-like receptors (TLR), which specifically recognize discrete pathogen associated molecular patterns. Ligation of TLRs on dendritic cells leads to their activation, the production of inflammatory cytokines such as IL-6, IL-12, tumor necrosis factor (TNF) and expression of co-stimulatory molecules [30].

Two major subsets of $\mathrm{T}$ cells are recognized, $\mathrm{CD}^{+} \mathrm{T}$ cells (also known as helper $\mathrm{T}$ cells) and $\mathrm{CD}^{+} \mathrm{T}$ cells (also known as cytotoxic $\mathrm{T}$ cells). $\mathrm{CD}^{+} \mathrm{T}$ cells produce IL-2, IL-4 and IL-5, which aid in the production of antibodies. IL-2 also helps to activate $\mathrm{CD}^{+}$cells to become fully functional cytotoxic cells equipped to kill virally infected, tumor, and allograft cells [25]. Both $\mathrm{CD} 4^{+}$and $\mathrm{CD}^{+} \mathrm{T}$ cells produce gamma interferon, which activates macrophages to produce pro-inflammatory cytokines and free radicals necessary for killing intracellular pathogens.

\subsection{PIP Involvement in Adaptive Immunity}

The binding and interaction of PIP to several components of the adaptive immune system has led to the speculation that it may be an important component of the adaptive immune system. Its interaction with some of these molecules, including the CD4 molecule on T cells, IgG, IL-4 and IL-13 as well as its inherent characteristic of an aspartyl protease are briefly summarized.

\subsubsection{PIP-CD4 Interactions}

CD4 acts as a signaling molecule during T cell activation and is a co-receptor for the interaction of $\mathrm{T}$ cell receptor (TCR) with the major histocompatibility complex class-II (MHC-11) molecule on antigen-presenting cells [31]. CD4 is also the primary viral receptor for Human Immunodeficiency Virus-1 (HIV-1) [32,33] that allows viral entry into T-helper lymphocytes. The interaction of CD4 with the HIV-1 envelope glycoprotein gp120 mediates attachment and penetration of the virus into the cell [34]. Autiero et al. [35] showed that the interaction of PIP with the first domain of CD4 induces a conformational change that disrupts the binding of HIV retrovirus to $\mathrm{CD}^{+}$cells and the post-binding events that follow. Also, it is well established that HIV infection induces immunosuppression by causing a loss of $\mathrm{CD}^{+} \mathrm{T}$ cells and that the interaction of PIP with CD4 on the T cell, blocks the forced apoptotic pathway that would normally occur [36]. Thus, PIP has the ability to inhibit this process, helping to sustain the adaptive immune response of the host that would otherwise be disturbed by the se- 
quential CD4/TCR triggering during a viral infection.

PIP has also been reported to bind to the D1-D2 region of CD4 with high affinity in human seminal plasma $[35,37]$. Human seminal plasma is known to have a wide array of effects on immune function. It is therefore possible that PIP interaction with CD4 may contribute to the immunosuppressive properties of human seminal plasma.

\subsubsection{Stimulation of PIP Expression by IL-4/IL-13}

It has been demonstrated that both IL-4 and IL-13 could act in breast cancer cells to regulate proliferation and protein expression [15]. Furthermore, NK cells isolated directly from the tumor site were shown to secrete an abundance of INF- $\gamma$ and IL-4 when compared to the cells collected from the patient's blood [38]. It has also been demonstrated that exposure of the breast cancer cell line, ZR-75, to IL-4 and IL-13, up-regulated PIP mRNA levels 5.5 and 6.0 fold, respectively [15]. Due to the observation that PIP binds to CD4 domains that interact with MHC-II molecules (that are involved in antigen recognition) [39], it is thus likely that the increase in PIP expression in response to IL-4 and IL-13 levels may modulate the activity of infiltrating $\mathrm{CD}^{+} \mathrm{T}$ cells [15], and thus contribute to the innate and adaptive immune response.

\subsubsection{PIP Binding to Ig $G$}

PIP has also been shown to bind to the constant region of IgG [40]. It has been proposed that the binding of PIP to IgG influences anti-sperm antibodies (ASA) and fertility [16]. However when the level of PIP in the seminal plasma of fertile men was compared to those of infertile men, there was no difference regardless of the status of ASA [40]. Thus, the evidence to support such a hypothesis is still lacking.

\subsubsection{Aspartyl Proteinase Activity of PIP}

Caputo et al. [19] showed for the first time that PIP was an aspartic protease. This was indeed an important observation as other aspartic proteases such as cathepsins $\mathrm{D}$ and $\mathrm{E}$ are known to play a role in the intracellular protein degradation in endosomes and lysosomes [41] and in so doing aspartic proteases are thought to serve an immune function. Once a pathogen is engulfed by a leukocyte, it is stored in the phagosome vesicle where it is later degraded. Using an in vitro assay it has been demonstrated that PIP could degrade fibronectin [19]. Indeed many molecules involved in the adaptive immune response start their signal transduction pathway on the cell surface. For instance, signals which originate from outside the cell (outside-in signals) generated by $\alpha 1 \beta 2$ integrins can act as a co-stimulus for the $\mathrm{T}$ cell receptor/CD3 complex, resulting in an IL-2 dependent proliferation of $\mathrm{T}$ cells [42]. Fibronectin has also been shown to specifically synergize with anti-CD3 antibody in the activation of the CD4 molecule [43], which plays a crucial role as a co-receptor that assists the $\mathrm{T}$ cell in communication with antigen presenting cells. Since fibronectin plays a central role in cell adhesion, the interaction of PIP with fibronectin may impact this pathway, resulting in a failure of the adaptive immune response to function appropriately, and thus could have detrimental effects on immune function.

The ability of PIP to degrade fibronectin may have yet other implications. For example, it has been demonstrated that many breast carcinomas have the ability to produce and secrete PIP [44]. PIP is usually weakly expressed or absent in normal breast tissue [19]. The discovery that PIP is an aspartyl protease suggests that it could play a role in the lytic processes associated with invasive breast cancer lesions [19]. This ability is common to other proteinases as well, such as matrix metalloproteinases [45] and secreted lysosomal enzymes [46]. Recently, Naderi et al., [47] showed that PIP mediates cell invasion and regulates integrin in breast cancer. Furthermore, secreted aspartyl proteinases are thought to contribute to the induction of an inflammatory host immune response as the addition of an aspartyl proteinase inhibitor was shown to strongly reduce the cytokine response to a C. albicans epithelial infection [48].

Thus, although definitive evidence showing a role for PIP in host immunity is lacking, its ability to potentially bind with several important host molecules including CD4, IgG, actin, zinc $\alpha 2$-glycoprotein (ZAG), fibronectin and enamel pellicle, suggests that it may have important biological functions [16,21-24,49]. However, despite these predicted functions, no study has clearly demonstrated the immunoregulatory role of PIP, particularly its role in modulating $\mathrm{CD}^{+} \mathrm{T}$ cells immune response in vitro or in vivo.

\section{INSIGHTS GAINED FROM THE PIP KO MOUSE MODEL: SUPPORTING EVIDENCE FOR AN IMMUNOREGULATORY ROLE}

To better understand the function of PIP, we generated a PIP knockout (KO) mouse model [50]. Mouse prolactin-inducible-protein (mPIP), also known as the mouse submaxillary gland protein (mSMGP), is a $14 \mathrm{kDa}$ protein and is the murine homologue of human PIP [11,51]. mPIP also displays $51 \%$ sequence identity with human PIP [8].

In terms of tissue specific expression, mPIP displays a high level of similarity to its human counterpart. Like the human PIP, mPIP expression was found to be strategically associated with tissues located at several ports of entry. The mRNA is highly expressed in both sailvary 
and lacrimal glands. As well, mPIP is found abundantly in the secretions of these glands, namely saliva and tears $[11,50]$. Importantly, the activities of both the human and mouse protein bear much similarity with regards to function. We demonstrated that MPIP can specifically bind to several bacterial strains, both human and mouse, including some within the genus Streptococcus, which are known to inhabit the oral cavity [52]. We further demonstrated that the binding of MPIP to the bacteria was capable of promoting bacterial aggregation and in so doing, possibly inhibiting further proliferation [52]. Such studies provide further key evidence to suggest that one of the functions of mPIP may be in antibacterial activities related to host defense.

In light of such evidence, the PIP KO mouse model provides an excellent tool to further address PIP function. Gross findings reveal no overt phenotypic changes and the PIP KO mice appear to grow and develop normally. However, histological analyses revealed enlarged submandibular lymph nodes, lymphocytic aggregations within the prostate lobes, enlarged medulla within the thymus, and cardiac arteritis and peri-arteritis [50]. Ulcerative colitis and dense infiltration of neutrophils in mucosa and lamina propria, as well as monocytic and lymphocytic infiltration in the gut associated lymphoid tissues of the intestine were also evident [50]. Furthermore, functional analyses of gene expression showed sets of differentially expressed genes associated with cell death and survival, inflammation, immune response and cancer [50].

\section{1. $\mathrm{mPIP}$ in Innate Immunity}

As well, we found that, when compared to wild type (WT) controls, there were both quantitative and compositional differences in the oral flora of PIP KO mice. Bacteria belonging to several different genera were identified in the oral cavity of both WT and PIP KO mice. However, Streptococci represented a higher proportion of the oral bacteria that inhabited the mouth of the PIP KO mice, when compared to the WT mice. Interestingly, we also observed that certain bacteria genera such as Neisseria were notably absent from the oral cavity of the PIP KO mice. As well, Gram negative rods isolated from WT mice were absent in PIP KO mice [53]. These findings strongly suggest that mPIP plays a role in regulating the colonization of the oral flora.

\subsection{Does PIP Play a Direct Role in Adaptive Immunity?}

In a recent study (unpublished data), we carried out indepth immunophenotypic analyses of primary and secondary lymphoid organs in order to compare them to WT counterpart mice. Although we observed no difference in the single positive $\left(\mathrm{CD}^{+} \mathrm{CD} 8^{-}\right.$and $\left.\mathrm{CD} 4^{-} \mathrm{CD} 8^{+}\right)$and double negative $\left(\mathrm{CD}^{-} \mathrm{CD}^{-}\right)$populations in the thymus and, that the percentages of NK and B cells were comparable, we found that the PIP KO mice had significantly lower numbers of $\mathrm{CD}^{+}$cells in their spleen and lymph nodes.

We further addressed the contributions of PIP in T cell responses to model antigens and infectious agents. Bone marrow dendritic cells (BMDCs) from PIP KO mice showed significantly lower expression of co-stimulatory molecules and pro-inflammatory cytokine production upon stimulation with different TLR agonists. In addition, naïve $\mathrm{CD}^{+} \mathrm{T}$ cells from PIP KO mice exhibited significantly impaired $\mathrm{T}$ helper cell type 1 differentiation (IFN- $\gamma$ production) in vitro and in vivo. Furthermore, PIP KO mice failed to control infection with Leishmania major as evidenced by progressive cutaneous lesion and inability to control parasite replication. Thus, our findings for the first time implicated PIP as an important $\mathrm{CD}^{+} \mathrm{T}$ cell modulatory protein that plays a critical role in effective cell-mediated immunity and resistance to an intracellular pathogen. On-going studies will further delineate the mechanisms through which PIP regulates $\mathrm{T}$ cell-mediated immunity in mice.

\section{CONCLUSION}

The PIP gene sequence is conserved across a broad range of species, suggesting that its retention may play a necessary role in the survival/fitness of a specie. To date, the function of this protein is still not clearly defined. However collectively, many studies indicate that the role of PIP is multifunctional. Moreover, recent studies from the PIP KO mouse model have provided strong supporting evidence to suggest that PIP plays a role in both an innate and adaptive immune host response to invading pathogens, and may be an important novel immunoregulatory molecule in host defense.

\section{ACKNOWLEDGEMENTS}

This work is supported by a grant from the Natural Sciences and Engineering Research Council of Canada (NSERC). The authors would like to acknowledge Anne Blanchard for reviewing and editing the manuscript.

\section{REFERENCES}

[1] Haagensen Jr., D.E. and Mazoujian, G. (1986) Diseases of the breast. W.B. Saunders, Philadelphia.

[2] Shiu, R.P. and Iwasiow, B.M. (1985) Prolactin-inducible proteins in human breast cancer cells. The Journal of Biological Chemistry, 260, 11307-11313.

[3] Murphy, L.C., Tsuyuki, D., Myal, Y. and Shiu, R.P. (1987) Isolation and sequencing of a cDNA clone for a prolac- 
tin-inducible protein (PIP). Regulation of PIP gene expression in the human breast cancer cell line, T-47D. The Journal of Biological Chemistry, 262, 15236-15241.

[4] Shiu, R.P., Murphy, L.C., Tsuyuki, D., Myal, Y., LeeWing, M. and Iwasiow, B. (1987) Biological actions of prolactin in human breast cancer. Recent Progress in Hormone Research, 43, 277-303.

[5] Caputo, E., Carratore, V., Ciullo, M., Tiberio, C., Mani, J.C., Piatier-Tonneau, D. and Guardiola, J. (1999) Biosynthesis and immunobiochemical characterization of gp17/ GCDFP-15. A glycoprotein from seminal vesicles and from breast tumors, in HeLa cells and in Pichia pastoris yeast. European Journal of Biochemistry, 265, 664-670. http://dx.doi.org/10.1046/j.1432-1327.1999.00758.x

[6] Akiyama, K. and Kimura, H. (1990) Isolation of a new actin-binding protein from human seminal plasma. Biochimica et Biophysica Acta, 1040, 206-210. http://dx.doi.org/10.1016/0167-4838(90)90077-S

[7] Schenkels, L.C., Schaller, J., Walgreen Weterings, E., Schadee Eestermans, I.L., Veerman, E.C. and Nieuw Amerongen, A.V. (1994) Identity of human extra parotid glycoprotein (EP-GP) with secretory actin binding protein (SABP) and its biological properties. Biological Chemistry Hoppe-Seyler, 375, 609-615. http://dx.doi.org/10.1515/bchm3.1994.375.9.609

[8] Myal, Y., Robinson, D.B., Iwasiow, B., Tsuyuki, D., Wong, P. and Shiu, R.P. (1991) The prolactin-inducible protein (PIP/GCDFP-15) gene: Cloning, structure and regulation. Molecular and Cellular Endocrinology, 80, 165-175.

http://dx.doi.org/10.1016/0303-7207(91)90153-J

[9] Myal, Y. and Shiu, R.P.C. (2000) The physiology and pathology of an apocrine protein: The prolactin-inducible protein (PIP)/gross cystic disease fluid protein (GCDFP15). Recent Research Developments in Endocrinology, pp. 321-335. Transworld Research Network, Trivandrum-8, India.

[10] Mazoujian, G., Pinkus, G.S., Davis, S. and Haagensen Jr., D.E., (1983) Immunohistochemistry of a gross cystic disease fluid protein (GCDFP-15) of the breast. A marker of apocrine epithelium and breast carcinomas with apocrine features. American Journal of Pathology, 110, 105112.

[11] Myal, Y., Iwasiow, B., Yarmill, A., Harrison, E., Paterson, J.A. and Shiu, R.P. (1994) Tissue-specific androgen-inhibited gene expression of a submaxillary gland protein, a rodent homolog of the human prolactin-inducible protein/GCDFP-15 gene. Endocrinology, 135, 1605-1610. http://dx.doi.org/10.1210/en.135.4.1605

[12] Haagensen Jr., D.E., Mazoujian, G., Dilley, W.G., Pedersen, C.E., Kister, S.J. and Wells Jr., S.A. (1979) Breast gross cystic disease fluid analysis. I. Isolation and radioimmunoassay for a major component protein. Journal of the National Cancer Institute, 62, 239-247.

[13] Haagensen, C.D., Bodian, C. and Haagensen, D.E. (1981) Lobular neoplasia (lobular carcinoma in situ). In: Haagensen, C.D., Ed., Breast carcinoma: Risk and Detection. Philadelphia, W. B. Saunders, Philadelphia, 1981. p. 238.

[14] Clark, J.W., Snell, L., Shiu, R.P., Orr, F.W., Maitre, N.,
Vary, C.P., Cole, D.J. and Watson, P.H. (1999) The potential role for prolactin-inducible protein (PIP) as a marker of human breast cancer micrometastasis. British Journal of Cancer, 81, 1002-1008. http://dx.doi.org/10.1038/sj.bjc.6690799

[15] Blais, Y., Gingras, S., Haagensen, D.E., Labrie, F. and Simard, J. (1996) Interleukin-4 and interleukin-13 inhibit estrogen-induced breast cancer cell proliferation and stimulate GCDFP-15 expression in human breast cancer cells. Molecular and Cellular Endocrinology, 121, 11-18. http://dx.doi.org/10.1016/0303-7207(96)03843-9

[16] Hassan, M.I., Waheed, A., Yadav, S., Singh, T.P. and Ahmad, F. (2009) Prolactin-inducible-protein in cancer, fertility and immunoregulation: Structure, function and its clinical implications. Cellular and Molecular Life Sciences, 66, 447-459.

http://dx.doi.org/10.1007/s00018-008-8463-x

[17] Rathman, W.M., Van Zeyl, M.J., Van den Keybus, P.A., Bank, R.A., Veerman, E.C. and Nieuw Amerongen, A.V. (1989) Isolation and characterization of three non-mucinous human salivary proteins with affinity for hydroxyapatite. Journal de Biologie Buccale, 17, 199-208.

[18] Rathman, W.M., Van Zeyl, M.J., van den Keijbus, P.A., Veerman, E.C. and Nieuw Amerongen, A.V. (1990) Comparison of a salivary $14 \mathrm{kD}$ protein displaying cysteine proteinase inhibitory activity with other salivary cystatins. Journal de Biologie Buccale, 18, 9-18.

[19] Caputo, E., Manco, G., Mandrich, L. and Guardiola, J. (2000) A novel aspartyl proteinase from apocrine epithelia and breast tumors. Journal de Biologie Buccale, 275, 7935-7941. http://dx.doi.org/10.1074/jbc.275.11.7935

[20] Miller, M., Jaskolski, M., Rao, J.K., Leis, J. and Wlodawer, A. (1989) Crystal structure of a retroviral protease proves relationship to aspartic protease family. Nature, 337, 576-579. http://dx.doi.org/10.1038/337576a0

[21] Anderson, S.T., Barclay, J.L., Fanning, K.J., Kusters, D.H., Waters, M.J. and Curlewis, J.D. (2006) Mechanisms underlying the diminished sensitivity to prolactin negative feedback during lactation: Reduced STAT5 signaling and up-regulation of cytokine-inducible SH2 domain-containing protein (CIS) expression in tuberoinfundibular dopaminergic neurons. Endocrinology, 147, 1195 1202. http://dx.doi.org/10.1210/en.2005-0905

[22] Chiu, W.W. and Chamley, L.W. (2003) Human seminal plasma prolactin-inducible protein is an immunoglobulin G-binding protein. Journal of Reproductive Immunology, 60, 97-111. http://dx.doi.org/10.1016/S0165-0378(03)00084-6

[23] Kumar, S., Tomar, A.K., Singh, S., Saraswat, M., Singh, S., Singh, T.P. and Yadav, S. (2012) Human serum albumin as a new interacting partner of prolactin-inducibleprotein in human seminal plasma. International Journal of Biological Macromolecules, 50, 317-322. http://dx.doi.org/10.1016/j.ijbiomac.2011.12.015

[24] Yoshida, M., Kaneko, M., Kurachi, H., and Osawa, M. (2001) Identification of two rodent genes encoding homologues to seminal vesicle autoantigen: A gene family including the gene for prolactin-inducible protein. Biochemical and Biophysical Research Communications, 281, 
94-100. http://dx.doi.org/10.1006/bbrc.2001.4311

[25] Levinson, W. (2010) Review of Medical Microbiology and Immunology. 11th Edition, McGraw-Hill, New York.

[26] Paul, W.E. (2008) Fundamental Immunology. 6th Edition, Lippincott Williams \& Wilkins, Philadelphia.

[27] Janeway Jr., C.A. and Medzhitov, R. (2002) Innate immune recognition. Annual Review of Immunology, 20, 197-216.

http://dx.doi.org/10.1146/annurev.immunol.20.083001.08 $\underline{4359}$

[28] Schenkels, L.C., Walgreen-Weterings, E., Oomen, L.C., Bolscher, J.G., Veerman, E.C., and Nieuw Amerongen, A.V. (1997) In vivo binding of the salivary glycoprotein EP-GP (identical to GCDFP-15) to oral and non-oral bacteria detection and identification of EP-GP binding species. Biological Chemistry, 378, 83-88. http://dx.doi.org/10.1515/bchm.1997.378.2.83

[29] Alberts, B., Johnson, A., Lewis, J., Raff, M., Roberts, K. and Walter, P. (2002) The adaptive immune system. In: Molecular Biology of the Cell, Garland Science, New York. http://www.ncbi.nlm.nih.gov/books/NBK21070/

[30] Warger, T., Osterloh, P., Rechtsteiner, G., Fassbender, M., Heib, V., Schmid, B., Schmitt, E., Schild, H. and Radsak, M.P. (2006) Synergistic activation of dendritic cells by combined toll-like receptor ligation induces superior CTL responses in vivo. Blood, 108, 544-550. http://dx.doi.org/10.1182/blood-2005-10-4015

[31] Zhou, W. and Konig, R. (2003) T cell receptor-independent CD4 signalling: CD4-MHC class II interactions regulate intracellular calcium and cyclic AMP. Cell Signaling, 15, 751-762.

http://dx.doi.org/10.1016/S0898-6568(03)00037-8

[32] Klatzmann, D., Champagne, E., Chamaret, S., Gruest, J., Guetard, D., Hercend, T., Gluckman, J.C. and Montagnier, L. (1984) T-lymphocyte T4 molecule behaves as the receptor for human retrovirus LAV. Nature, 312, 767-768. http://dx.doi.org/10.1038/312767a0

[33] Maddon, P.J., Dalgleish, A.G., McDougal, J.S., Clapham, P.R., Weiss, R.A. adn Axel, R. (1986) The T4 gene encodes the AIDS virus receptor and is expressed in the immune system and the brain. Cell, 47, 333-348. http://dx.doi.org/10.1016/0092-8674(86)90590-8

[34] McDougal, J.S., Nicholson, J.K., Cross, G.D., Cort, S.P., Kennedy, M.S. and Mawle, A.C. (1986) Binding of the human retrovirus HTLV-III/LAV/ARV/HIV to the CD4 (T4) molecule: Conformation dependence, epitope mapping, antibody inhibition, and potential for idiotypic mimicry. The Journal of Immunology, 137, 2937-2944.

[35] Autiero, M., Gaubin, M., Mani, J.C., Castejon, C., Martin, M., El, M.S., Guardiola, J. and Piatier-Tonneau, D. (1997) Surface plasmon resonance analysis of gp17, a natural CD4 ligand from human seminal plasma inhibiting human immunodeficiency virus type-1 gp120-mediated syncytium formation. European Journal of Biochemistry, 245, 208-213. http://dx.doi.org/10.1111/j.1432-1033.1997.00208.x

[36] Gaubin, M., Autiero, M., Basmaciogullari, S., Metivier, D., Mis, H.Z., Culerrier, R., Oudin, A., Guardiola, J. and Piatier-Tonneau, D. (1999) Potent inhibition of CD4/TCR-me- diated $\mathrm{T}$ cell apoptosis by a CD4-binding glycoprotein secreted from breast tumor and seminal vesicle cells. Journal of Immunology, 162, 2631-2638.

[37] Autiero, M., Abrescia, P. and Guardiola, J. (1991) Interaction of seminal plasm proteins with cell surface antigens: Presence of a CD4-binding glycoprotein in human seminal plasma. Experimental Cell Research, 197, 268-271. http://dx.doi.org/10.1016/0014-4827(91)90432-T

[38] Lorenzen, J., Lewis, C.E., McCracken, D., Horak, E., Greenall, M. and McGee, J.O. (1991) Human tumour-associated NK cells secrete increased amounts of interferon-gamma and interleukin-4. British Journal of Cancer, 64, 457-462. http://dx.doi.org/10.1038/bjc.1991.331

[39] Autiero, M., Cammarota, G., Friedlein, A., Zulauf, M., Chiappetta, G., Dragone, V. and Guardiola, J. (1995) A 17-kDa CD4-binding glycoprotein present in human seminal plasma and in breast tumor cells. European Journal of Immunology, 25, 1461-1464. http://dx.doi.org/10.1002/eji.1830250550

[40] Chiu, W.W. and Chamley, L.W. (2002) Antibody-binding proteins in human seminal plasma. American Journal of Reproductive Immunology, 48, 269-274. http://dx.doi.org/10.1034/j.1600-0897.2002.01122.x

[41] Lin, X., Koelsch, G., Wu, S., Downs, D., Dashti, A. and Tang, J. (2000) Human aspartic protease memapsin 2 cleaves the beta-secretase site of beta-amyloid precursor protein. Proceedings of National. Academy of Sciences of the United States of America, 97, 1456-1460. http://dx.doi.org/10.1073/pnas.97.4.1456

[42] Van Seventer, G.A., Shimizu, Y., Horgan, K.J. and Shaw, S. (1990) The LFA-1 ligand ICAM-1 provides an important costimulatory signal for $\mathrm{T}$ cell receptor-mediated activation of resting T cells. Journal of Immunology, 144, 4579-4586.

[43] Matsuyama, T., Yamada, A., Kay, J., Yamada, K.M., Akiyama, S.K., Schlossman, S.F. and Morimoto, C. (1989) Activation of CD4 cells by fibronectin and anti-CD3 antibody. A synergistic effect mediated by the VLA-5 fibronectin receptor complex. Journal of Experimental Medicine, 170, 1133-1148. http://dx.doi.org/10.1084/jem.170.4.1133

[44] Wick, M.R., Lillemoe, T.J., Copland, G.T., Swanson, P.E., Manivel, J.C. and Kiang, D.T. (1989) Gross cystic disease fluid protein-15 as a marker for breast cancer: Immunohistochemical analysis of 690 human neoplasms and comparison with alpha-lactalbumin. Human Pathology, 20, 281-287. http://dx.doi.org/10.1016/0046-8177(89)90137-8

[45] Basset, P., Bellocq, J.P., Wolf, C., Stoll, I., Hutin, P., Limacher, J.M., Podhajcer, O.L., Chenard, M.P., Rio, M.C. and Chambon, P. (1990) A novel metalloproteinase gene specifically expressed in stromal cells of breast carcinomas. Nature, 348, 699-704. http://dx.doi.org/10.1038/348699a0

[46] Chauhan, S.S., Goldstein, L.J. and Gottesman, M.M. (1991) Expression of cathepsin L in human tumors. Cancer Research, 51, 1478-1481.

[47] Naderi, A. and Meyer, M. (2012) Prolactin-induced protein mediates cell invasion and regulates integrin signal- 
ing in estrogen receptor-negative breast cancer. Breast Cancer Research, 14, R111. http://dx.doi.org/10.1186/bcr3232

[48] Schaller, M., Korting, H.C., Borelli, C., Hamm, G. and Hube, B. (2005) Candida albicans-secreted aspartic proteinases modify the epithelial cytokine response in an in vitro model of vaginal candidiasis. Infection and Immunity, 73, 2758-2765. http://dx.doi.org/10.1128/IAI.73.5.2758-2765.2005

[49] Hassan, M.I., Bilgrami, S., Kumar, V., Singh, N., Yadav, S., Kaur, P. and Singh, T.P. (2008) Crystal structure of the novel complex formed between zinc $\alpha 2$-glycoprotein (ZAG) and prolactin-inducible protein (PIP) from human seminal plasma. Journal of Molecular Biology, 384, 663672. http://dx.doi.org/10.1016/j.jmb.2008.09.072

[50] Blanchard, A., Nistor, A., Castaneda, F.E., Martin, D., Hicks, G.G., Amara, F., Shiu, R.P. and Myal, Y. (2009) Generation and initial characterization of the prolactin-inducible protein (PIP) null mouse: Accompanying global changes in gene expression in the submandibular gland. Canadian Journal of Physiology and Pharmacology, 87, 859-872. http://dx.doi.org/10.1139/Y09-077

[51] Windass, J.D., Mullins, J.J., Beecroft, L.J., George, H., Meacock, P.A., Williams, B.R. and Brammar, W.J. (1984) Molecular cloning of cDNAs from androgen-independent mRNA species of DBA/2 mouse sub-maxillary glands. $\mathrm{Nu}$ cleic Acids Research, 12, 1361-1376. http://dx.doi.org/10.1093/nar/12.3.1361

[52] Lee, B., Bowden, G.H. and Myal, Y. (2002) Identification of mouse submaxillary gland protein in mouse saliva and its binding to mouse oral bacteria. Archives of Oral Biology, 47, 327-332. http://dx.doi.org/10.1016/S0003-9969(01)00113-3

[53] Nistor, A. (2008) Investigations into the role of mPIP, the mouse homologue of hPIP/GCDFP-15, in innate host defense. Master Thesis, University of Manitoba, Winnipeg. 